\title{
Immunisation of Armed Service Medical Personnel Against Hepatitis B Infection
}

\author{
Maj NS Cumberland \\ MRCPath, RAMC* \\ Consultant Microbiologist \\ Lt Col JM Sloss \\ MRCPath, RAMC** \\ Consultant Microbiologist
}

Department of Pathology, Queen Elizabeth Military Hospital, Stadium Road, London SE18 4QH

\section{Sqn Ldr AD Green}

MRCPath, RAF

Consultant Microbiologist

Sqn Ldr RG Masterton

MRCPath, RAF***

Consultant Microbiologist

Royal Air Force Institute of Pathology and Tropical Medicine, Halton, Aylesbury, Bucks, HP22 SPQ

\section{Mrs MM Sims}

BSc

Statistician

Ministry of Defence, Medical Statistics, Stanmore, Middlesex HA7 4PZ

SUMMARY: Clinical and laboratory staff of the Army and RAF medical services at risk of acquiring infection with hepatitis $B$ were immunised against the virus with a recombinant vaccine. Vaccine was administered in Service hospitals and medical centres located throughout the world.

After a primary course of vaccine, $73 \%$ of personnel developed anti-HBs titres $\geq 100 \mathrm{IU} / \mathrm{L}$ to hepatitis B surface antigen and were considered protected; $11 \%$ were non-responders (anti-HBs < 10 IU/l). A significantly higher proportion of females than males, and vaccinees under $\mathbf{4 0}$ years of age, produced a good response.

Among those achieving a good response, antibody titres were higher in the younger age group and in females. After a fourth (booster) dose of vaccine, $\mathbf{8 7 . 2 \%}$ of the poor responders and $37 \%$ non-responders, developed antiHBs titres $\geq 100 \mathrm{IU} / \mathrm{L}$.

\section{Introduction}

Infection with hepatitis B virus (HB) is a major occupational risk for all clinical care personnel with direct patient contact and exposure to infected blood and body fluids (1). Health care personnel in the Armed Services are equally at risk of infection but in addition they are more mobile than their colleagues in civilian life. They may be required, frequently and at short notice, to work in countries located in sub-Saharan Africa, Central America, South East Asia and recently the Middle East and Eastern Europe where the prevalence of hepatitis B infection and its chronic carriage in the indigenous populations is higher than that in the United Kingdom (UK) $(2,3,4)$.

* now Frimley Park Hospital, Surrey

** now BMH Rinteln, BFPO 31

*** now Western General Hospital, Edinburgh
Immunisation against hepatitis B virus has been available to medical staff at risk of infection for several years and is one of the accepted preventive measures. Studies of hepatitis B immunisation in health service staff in the UK have demonstrated that the vaccines are both safe and immunogenic $(5,6,7,8)$.

Following the introduction of a Joint Services Policy (9), a programme for voluntary vaccination against hepatitis $B$ virus, using a recombinant vaccine, was started for Service personnel who will be at occupational risk of acquiring hepatitis $B$ infection.

From 1st July 1994 it has been Ministry of Defence policy that all surgeons must have completed a course of 
hepatitis B immunisation and been shown to have a good response. Those individuals who have not responded to the vaccine after a booster dose are to be tested for markers of hepatitis $B$ infection. If found to be $\mathrm{HBe}$ antigen positive then they are to stop 'exposure prone procedures' and be referred for occupational advice and treatment. This policy will be extended on 1st July 1995 to include all individuals who perform 'exposure prone procedures'. This study reports an analysis of the antibody responses in a large mobile population of Service health care personnel after receiving a recombinant hepatitis $B$ vaccine in centres located worldwide.

\section{Methods and Materials}

From January 1988 onwards a recombinant (yeastderived) hepatitis $B$ surface antigen vaccine was administered to 3253 Service health care personnel (aged 17 to 65 years) at risk of occupational exposure to hepatitits B virus and their post-immunisation anti-HBs titres were determined. Vaccinees were surgical, medical, dental, nursing and laboratory staff of the Army and the RAF medical services. Personnel received the vaccine at four RAF Hospitals in the UK, West Germany and Cyprus and at the RAF Institute of Pathology and Tropical Medicine, Halton and at seven Army hospitals (plus associated medical and dental centres) in the UK, West Germany, Hong Kong and at the Royal Army Medical College (RAM College).

Vaccination programmes were administered by hospital, medical and dental centre based general practitioners and their staff.

Each individual received a $1 \mathrm{ml}$ dose $(20 \mu \mathrm{g} / \mathrm{ml}$ antigen protein) of recombinant vaccine (Engerix B; Smith Kline Beecham Pharmaceuticals, Hertordshire, U.K.) into the deltoid muscle, on day one and at 1 month and 6 months thereafter, according to the manufacturer's recommendations.

An accelerated vaccination schedule was used for 55 male Service personnel; doses given at 0,1 and 2 months as recommended by the Departments of Health (10).

Blood samples were collected from all vaccinees between 8 and 12 weeks after the third dose of vaccine and the serum stored at $-40^{\circ} \mathrm{C}$ until assayed.
Antibodies to hepatitis B surface antigen (anti-HBs) i post-immunisation sera were measured by quantitative enzyme-linked immunoassays; Organon Teknika AntiHBs (Organon Teknika Limited, Cambridge. UK) waš used at RAF Halton and 'Ausab' EIA and 'Ausabo Quantitation Panel (Abbott Laboratories, North Chicago IL) at RAM College. One hundred sera were analysed by both methods and no significant difference found betweers? results.

The recommendations of the International Group fo the interpretation of the levels of anti-HBs antibodies after immunisation were followed throughout this stud $\$$ (11): individuals with anti-HBs titres $\leq 10$ Internationa\$ Units per litre (IU/L) were considered to be non $\rightarrow$ responders and not protected, those with titres $\geq 10$ and $<100 \mathrm{IU} / \mathrm{L}$ as poor responders and those with titres $\geq 10 \mathrm{~W}$ IU/L as good responders with long term protection.

Non-responders and poor responders to the primary course of vaccine were given a fourth $1 \mathrm{ml}(20 \mathrm{ug} / \mathrm{ml}$ ह booster dose of vaccine and blood samples were collected for anti-HBs assay between 8 and 12 weeks afterwards.

\section{Statistical Methods}

Response data were analysed by the GLIM package (12) using multiple logistic regression, with sex, ade? Service and pre-booster antibody response group factors and estimation by the method of maxim\&n likelihood. The odds ratios produced (with th@ $\Phi$ associated confidence intervals and significance le testing the null hypothesis of no association between the factors and antibody response) represented the risk raipo in going from one level of a factor to the other (13). A All the risk ratios reported were stratified to remo anomalies due to the uenven distributions of the factors ow interest.

\section{Results}

Of the 3253 vaccinees, post-immunisation antibody titres and vaccination schedules were available for 287 若 $(88.3 \%$; 1636 females and 1235 males) and of these, dati for age were also available for 2729 individuals (157 females, 1158 males).

The highest uptake of vaccination was by operating theatre technicians (95\%), followed by dental surgeon

Table 1

Antibody Response to Hepatitis B Vaccine in Armed Service Medical Personnel: Post-Immunisation Titres of Anti-HBs (IU/L)

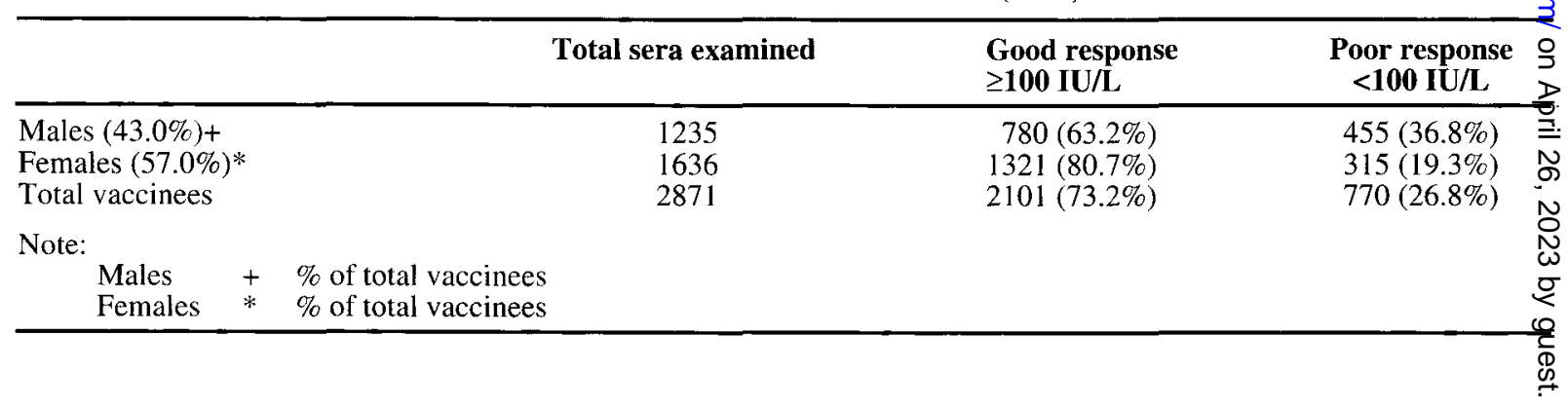


Table 2

Antibody Response to Hepatitis B Vaccine - Effect of Age on Post-Immunisation Anti-HBs Titres in Female Vaccinees

\begin{tabular}{lccc}
\hline Age (Years) & Total sera examined & Good response $\geq \mathbf{1 0 0} \mathbf{I U} / \mathbf{L}$ & Poor response $<\mathbf{1 0 0}$ IU/L \\
\hline $17-29$ & 986 & $835(84.7 \%)$ & $151(15.3 \%)$ \\
$30-39$ & 381 & $289(75.9 \%)$ & $92(24.1 \%)$ \\
$40-49$ & 139 & $108(77.7 \%)$ & $31(22.3 \%)$ \\
$50-65$ & 65 & $37(56.9 \%)$ & $28(43.1 \%)$ \\
Total vaccinees & 1571 & $1269(80.8 \%)$ & $302(19.2 \%)$ \\
\hline
\end{tabular}

Table 3

Antibody Response to Hepatitis B Vaccine - Effect of Age on Post-Immunisation Anti-HBs Titres in Male Vaccinees

\begin{tabular}{lccc}
\hline Age (Years) & Total sera examined & Good response $\geq \mathbf{1 0 0}$ IU/L & Poor response < 100 IU/L \\
\hline $17-29$ & 594 & $400(67.3 \%)$ & $194(32.7 \%)$ \\
$30-39$ & 355 & $217(61.1 \%)$ & $138(38.9 \%)$ \\
$40-49$ & 152 & $83(54.6 \%)$ & $69(45.4 \%)$ \\
$50-65$ & 57 & $26(45.6 \%)$ & $31(54.4 \%)$ \\
Total vaccinees & 1158 & $726(62.7 \%)$ & $432(37.3 \%)$ \\
\hline
\end{tabular}

$(90 \%)$, dental assistants and laboratory staff (both $85 \%$ ), nursing staff $(75 \%)$ and physicians and surgeons $(66 \%)$.

The reasons for not undergoing vaccination were determined for 139 personnel. The majority, $60 \%$, intended to seek vaccination in the future; a further $20 \%$ considered themselves not to be at risk; followed by difficulty in arranging vaccination $7.5 \%$; unspecified $6 \%$; fears for vaccine safety or effectiveness $3.5 \%$ and needle phobia $3 \%$.

After a primary course, $88.9 \%$ of 2871 vaccinees overall responded to the vaccine $(\geq 10 \mathrm{IU} / \mathrm{L})$, and $73.2 \%$ developed a good response (anti-HBs titre $\geq 100 \mathrm{IU} / \mathrm{L}$ ), Table 1. More males than females produced a poor response to vaccine $(36.8 \%$ compared to $19.3 \%)$. Using date from 2729 individuals the risk ratio (odds ratio or approximate relative risk) of poor response if male, and stratified by Service, is $2.48 \%$ overall $(95 \%$ CI 2.09 $2.93, \mathrm{p}<0.0001)$.
Tables 2 and 3 show that the antibody response to $\triangle$ vaccine is poorer with increasing age in both sexes. When the results are stratified by gender and Service, the risk $\varnothing$ ratio of poor response if 40 years of age or over is $1.77 \%$ $(95 \%$ CI $1.42-2.22, \mathrm{p}<0.0001)$.

A significant difference in antibody response due to gender has been demonstrated and the results are very similar when additionally stratified for age. Among 2729 vaccinees with documented age and gender, $310(11.4 \%)$ were classified as non-responders (anti-HBs <10 IU/L). Table 4 shows that non-response to hepatitis $B$ vaccine is associated with male gender; $16.8 \%$ of male vaccinees compared with $7.4 \%$ female vaccinees were nonresponders, (the risk ratio is $2.5095 \% \mathrm{CI}, 1.95-3.19$, p $\ll 0.0001$ ), and, to a lesser extent with increasing age, the risk ratio of non-response if 40 years of age or over is $1.56(95 \% \mathrm{CI}, 1.16-2.10,0.001<\mathrm{p}<0.005)$.

Table 4

Distribution of Non-Responders (Anti-HBs < 10 IU/L) by Age and Gender

\begin{tabular}{|c|c|c|c|}
\hline Age (Years) & Male & Female & Combined \\
\hline $17-29$ & $85 / 594 \quad(14.3 \%)$ & $58 / 986 \quad(5.8 \%)$ & $143 / 1580 \quad(9.0 \%)$ \\
\hline $30-39$ & $59 / 355(16.6 \%)$ & $40 / 381(10.5 \%)$ & $99 / 736(13.5 \%)$ \\
\hline $40-49$ & $37 / 152(24.3 \%)$ & $13 / 139 \quad(9.3 \%)$ & $50 / 291 \quad(17.2 \%)$ \\
\hline $50-65$ & $13 / 57 \quad(22.38 \%)$ & $5 / 65 \quad(7.7 \%)$ & $18 / 122(14.8 \%)$ \\
\hline Total vaccinees & $194 / 1158(16.8 \%)$ & $116 / 1571(7.4 \%)$ & $310 / 2729(11.4 \%)$ \\
\hline
\end{tabular}


Table 5

Response to Fourth (Booster) Dose of Hepatitis Vaccine

\begin{tabular}{|c|c|c|c|c|}
\hline \multirow{2}{*}{$\begin{array}{l}\text { Titre } \\
\text { Pre-Booster }\end{array}$} & \multirow{2}{*}{\multicolumn{2}{|c|}{ Total Sera Examined }} & \multicolumn{2}{|c|}{ Anti-HBs Titre Post-Booster } \\
\hline & & & $<100$ IU/L & $\geq 100 \mathrm{IU} / \mathrm{L}$ \\
\hline$<10 \mathrm{IU} / 1$ & $\begin{array}{l}\text { ( Male } \\
\text { ( Female } \\
\text { ( Combined }\end{array}$ & $\begin{array}{l}49 \\
43 \\
92\end{array}$ & $\begin{array}{l}30(61.1 \%) \\
28(65.1 \%) \\
58(63.0 \%)\end{array}$ & $\begin{array}{l}19(38.8 \%) \\
15(34.9 \%) \\
34(37.0 \%)\end{array}$ \\
\hline $10-99 \mathrm{IU} / 1$ & $\begin{array}{l}\text { ( Male } \\
\text { (Female } \\
\text { (Combined }\end{array}$ & $\begin{array}{r}53 \\
56 \\
109\end{array}$ & $\begin{array}{r}8(15.1 \%) \\
6(10.7 \%) \\
14(12.8 \%)\end{array}$ & $\begin{array}{l}45(84.9 \%) \\
50(89.3 \%) \\
95(87.2 \%)\end{array}$ \\
\hline Total & & 201 & $72(35.8 \%)$ & $129(64.2 \%)$ \\
\hline
\end{tabular}

Table 6

Distribution of Anti-HBs Titres in Good Responders ( $\geq 100$ IU/1) by Age and Gender

\begin{tabular}{|c|c|c|c|c|c|c|c|}
\hline \multirow{4}{*}{$\begin{array}{l}\text { Age } \\
\text { (yrs) }\end{array}$} & \multirow{2}{*}{\multicolumn{4}{|c|}{$\begin{array}{l}\text { Anti/HBs Titre (IU/1) } \\
100-999\end{array}$}} & \multirow{2}{*}{\multicolumn{2}{|c|}{$\geq 1000$}} & \\
\hline & & & & & & & \\
\hline & \multicolumn{2}{|c|}{ Number } & \multirow{2}{*}{$\begin{array}{l}\text { Male } \\
\text { No }(\%)\end{array}$} & \multirow{2}{*}{$\begin{array}{l}\text { Female } \\
\text { No }(\%)\end{array}$} & \multirow{2}{*}{$\begin{array}{l}\text { Male } \\
\text { No }(\%)\end{array}$} & \multirow{2}{*}{$\begin{array}{l}\text { Female } \\
\text { No }(\%)\end{array}$} & \multirow{2}{*}{$\begin{array}{r}\stackrel{ }{+} \\
\text { 끙 } \\
0\end{array}$} \\
\hline & Male & Female & & & & & \\
\hline $17-29$ & 207 & 422 & $61(29.5)$ & $117(27.7)$ & $146(70.5)$ & $305(72.3)$ & \\
\hline $30-39$ & 109 & 112 & $51(46.8)$ & $34(30.4)$ & $58(53.2)$ & $78(69.6)$ & \\
\hline $40-65$ & 56 & 63 & $29(51.8)$ & $21(33.3)$ & $27(48.2)$ & $42(66.7)$ & 2 \\
\hline Total: All ages & 372 & 597 & $141(37.9)$ & $172(28.8)$ & $231(62.1)$ & $425(71.2)$ & \\
\hline \multirow{5}{*}{$\begin{array}{l}\text { Total: } \\
\text { (All ages, both sexes) }\end{array}$} & \multicolumn{2}{|c|}{969} & \multicolumn{2}{|c|}{$313(32.3)$} & \multicolumn{2}{|c|}{$656(67.7)$} & \\
\hline & \multirow{2}{*}{\multicolumn{6}{|c|}{$\begin{array}{r}\text { Antibo } \\
\text { Do }\end{array}$}} & \\
\hline & & & & & & & \\
\hline & \multicolumn{4}{|c|}{ Anti/HBs Titre (IU/L) } & \multirow{2}{*}{\multicolumn{2}{|c|}{ TOTAL }} & \\
\hline & & 10-99 & $\geq 100$ & & & \\
\hline Number & 16 & & \multirow{2}{*}{$\begin{array}{l}25 \\
55.4\end{array}$} & 14 & & \\
\hline Percentage & \multicolumn{2}{|c|}{29.1} & & 25.5 & \multicolumn{2}{|c|}{100.0} & \\
\hline
\end{tabular}

A fourth dose of vaccine was given to 201 of 770 (26\%) Service personnel who produced a poor response (anti-HBs $<100 \mathrm{IU} / \mathrm{L}$ ) after the primary course of vaccine. Of these, $129(64.2 \%)$ produced a good response (anti-HBs $\geq 100 \mathrm{IU} / \mathrm{L}$ ) (Table 5). There was no indication that females responded better than males to the fourth dose of vaccine.

A notable result was the highly significant benefit of giving a booster dose to individuals, who, after a primary course of vaccine, had responded with relatively higher initial titres (anti-HBs $>10$ but $<100 \mathrm{IU} / \mathrm{L}$ ). Overall, $87.2 \%$ of these vaccinees produced anti-HBs $\geq 100 \mathrm{IU} / \mathrm{L}$ after a fourth dose, compared to $37.0 \%$ who produced good response after initial titres of $<10 \mathrm{IU} / \mathrm{L}$. Stratifyini results by gender and Service gives a relative benefit o the higher initial titres of $12.04(95 \% \mathrm{CI}, 5.87-24.70$, 驾 very small).

Data for Army personnel alone indicate that the mear titres of antibodies after giving a fourth dose to ar. individual with an initial titre of $\geq 10 \mathrm{IU} / \mathrm{L}$, were 44000 IU/L for males (range 42 to $10,000 \mathrm{IU} / \mathrm{L}$ ) and $3000 \mathrm{IU} / \mathrm{INO}$ for females (range 43 to $10,000 \mathrm{IU} / \mathrm{L}$ ). In contrast, after d fourth dose of vaccine in individuals with an initial titro of $<10 \mathrm{IU} / \mathrm{L}$, the mean antibody titres were $80 \mathrm{IU} / \mathrm{L}$ for 
males (range $<10$ to 255 ) and $150 \mathrm{IU} / \mathrm{L}$ for females (range $<10$ to 1200 ).

Nine subjects who had produced anti-HBs titres of between 0 and $43 \mathrm{IU} / \mathrm{L}$ after a primary course of vaccine plus one booster, received a fifth (second booster) dose of vaccine; of these, only 4 produced anti-HBs titres $\geq 100$ IU/L.

Table 6 shows the anti-HBs titres for 969 (46\%) of the 2101 Service personnel who produced a good response (anti-HBs $\geq 100 \mathrm{IU} / \mathrm{L}$ ) after a primary course of vaccine. Of those, $656(67.7 \%)$ produced titres of anti-HBs $\geq 1000$ IU/L, and, of these, 233 (24\% of the total 969) produced titres $\geq 5000 \mathrm{IU} / \mathrm{L}$. Anti-HBs titres were related to the age and the gender of the vaccinee. A greater proportion of vaccinees in the age group 17 - 29 years produced antiHBs $\geq 1000 \mathrm{IU} / \mathrm{L}$ when compared to the two older age groups, and a higher proportion of females than males produced titres $\geq 1000 \mathrm{IU} / \mathrm{L}$, particularly in the two older age groups. Table 7 shows the anti-HBs titres produced in the 55 male Army personnel aged 17 to 36 years following an accelerated vaccination schedule. Development of anti-HBs ( $>10 \mathrm{IU} / \mathrm{L}$ ) was achieved by $70.9 \%$ of vaccinees and $25.5 \%$ produced a good response within 8 to 12 weeks of the third dose of vaccine.

\section{Discussion}

Hepatitis B virus infection, acquired through percutaneous and mucous membrane exposure to infected blood, is a major occupational risk for clinical and laboratory staff. The availability of a vaccine to these individuals offers a safe and effective means of protection, the probability of transmission of infection to health care personnel who have proven immunity being virtually nil $(1,14,15)$.

The antibody responses produced in Service vaccinees in this study were comparable with those recently reported for health service staff using recombinant vaccines and performed in single locations in the UK $(6$, 7,8 ). The overall proportion of Service personnel, $88.9 \%$, responding to this recombinant vaccine (anti-HBs $\geq 10$ IU/L) was similar to that found in earlier studies $(7,8)$. Furthermore, $73 \%$ of Service vaccinees produced antiHBs $\geq 100 \mathrm{IU} / \mathrm{L}$, a result which also is comparable with the $76 \%$ reported by Westmoreland et al. (7).

The influence of age on antibody response to this recombinant vaccine has been described previously $(7,8)$. This present study indicates that with increasing age a decreasing proportion of vaccinees produce protective levels of antibodies.

This study has shown also a statistically significant influence of gender upon the antibody response to recombinant vaccine, an effect reported previously $(7,8$, 16). A greater proportion of females than males in all age groups in the Service population consistently produced a good antibody response, with higher titres of anti-HBs.

In common with previous reports $(7,8)$, this study found poor responders in both sexes in all age groups tested, and particularly in males aged 40 years and over. Even in the most responsive group, namely females aged 17 to 29 years (34\% of the total Service vaccinees), approximately $15 \%$ did not produce a good antibody response.

In our population the overall proportion of nonresponders to a primary course of vaccine was $11.1 \%$ and was related to the age and gender of the vaccinee. This is directly comparable with previous studies using recombinant vaccines which have reported $9.5 \%$ and $14 \%$ non-responders respectively $(7,8)$.

This study confirms the work of Westmoreland et al (7) and indicates that being male and in an older age group has independent adverse effects on the likelihood that an individual will produce a protective antibody response ( anti-HBs $\geq 100 \mathrm{IU} / \mathrm{L}$ ) to hepatitis $\mathrm{B}$ vaccine.

These differences in antibody response strongly support the recommendation to determine postimmunisation anti-HBs titres in all vaccinees after completion of a primary course of vaccine, regardless of gender or age, in order that further doses may be given to poor responders $(7,10)$. A poor response to hepatitis B vaccine in a healthy subject may be due not only to age and gender but also to a genetically determined immuneo response to $\mathrm{HBs}$ antigen (17), incorrect vaccine administration, the timings of post-immunisation titres $\Omega$ variations in vaccine batches and conditions of storage of vaccine (e.g. not maintaining a cold chain in ho응 climates). In addition, poor response to hepatitis $B$ or vaccine has been associated with obesity $(18,19,20)$ cigarette smoking $(20,21)$ and alcohol consumption (20) These factors should be considered when performing ande interpreting an immunisation schedule with this vaccine.

The antibody responses by our subjects who were poor or non-responders to a primary course of vaccine, and who then received a fourth dose, were similar to that reported by Rogan (8) and greater than that reported by Westmoreland et al. (7). In our study, nearly two thirds of subjects overall, $37 \%$ of non-responders and nearly $90 \%$ of poor responders to a primary course, subsequently produced a good response after a further dose of vaccine, thus indicating that the majority of vaccinees responding to a primary course with anti-HBs $<100 \mathrm{IU} / \mathrm{L}$ will require only a single booster dose to produce a good response. Despite education programmes, recent reports suggest that the uptake of vaccination among health care personnel has remained low $(22,23,24)$, and that a large proportion of surgeons in particular have not had their post-immunisation titres of anti-HBs determined $(23,24)$. Our study showed that uptake of vaccine was high in operating theatre and dental staff, whereas about a third of surgeons and physicians had not been vaccinated. The predominant reasons given by our population for remaining unvaccinated (future intent and perceived low risk) were consistent with those reported in past studies $(24,25)$. 
Recently published guidelines recommend that all health care workers who perform 'exposure prone procedures' in which injury to the worker could result in blood contaminating the patient's open tissues should be immunised against infection with hepatitis B virus, and their post-immunisation antibody titres determined (26, 27). Surgeons who remain unprotected are not only at risk of acquiring hepatitis B infection, but may also transmit infection to their patients (28), both of which hazards may have implications for future careers $(26,27,28,29)$. Penetrative injuries sustained by medical students and junior doctors are reported to be frequent $(25,30,31)$, and immunisation early in a career and at an age when a good antibody response is more likely, would ensure protection against infection and compliance with guidelines (27).

During this study, considerable organisation was required to complete the vaccination schedules for Service personnel world-wide and to obtain postimmunisation antibody titres. Despite these efforts, during the period of study over $10 \%$ of our vaccinees were lost to follow-up and only $26 \%$ of poor responders received a booster dose with documentation of subsequent anti-HBs titres; another important factor to be borne in mind with regular movements of Service personnel.

There still remains a pool of 50,000 people in Britain who are HBs Ag carriers, $10 \%$ of whom are highly infectious (32); thus the risk to personnel of infection may exceed $30 \%$ after a penetrative injury involving $\mathrm{HBe}$ antigen positive hepatitis B infected blood (33).

A previous study showed no significant difference between the incidence rates of hepatitis B in NHS personnel and Armed Services medical staff, and no evidence that soldiers or their dependants pose a greater risk of hepatitis B infection to medical staff than the general civilian population in the UK (34). The study recommended that Service medical staff should be offered the same opportunity for immunisation as NHS personnel, particularly when practising in countries with a higher risk of infection than the UK: there are over 260 million carriers of the virus in the endemic regions of Africa and Asia (35).

An accelerated vaccination schedule, which rapidly produces protective levels of antibodies, would be beneficial for Service personnel on short notice for movement to areas of high prevalence of infection and for accelerated post-exposure prophylaxis. The accelerated schedule used in this study and previously described (10); and that used in two recent studies in which vaccine was given at 0,2 and 6 weeks produced anti-HBs $\geq 10 \mathrm{IU} / \mathrm{L}$ in $71 \%, 87 \%$ and $94 \%$ respectively $(36,37)$.

Furthermore, the schedule used in this study (10), and that of Harries et al (36) produced a good response $(\geq 100$ IU/L) on $25 \%$ and $43 \%$ of vaccinees respectively.

Nevertheless, determination of post-immunisation antiHBs titres remains necessary so that a fourth dose of vaccine may be given at 12 months to achieve long term protective antibody levels (38).

This study confirms the immunogenicity of recombinant hepatitis $B$ vaccine, using the manufacturer's $\Omega$ recommended schedule in Service medical personnelo vaccinated in locations throughout the world. Response is affected by the age and gender of the vaccinee, with the best responses observed in young females, who comprise a large proportion of the Service health care population ato risk. The majority of our vaccinees responded with high을 titres of anti-HBs, which should ensure reliable protection $\frac{\bar{p}}{\vec{D}}$ until the recommended time for booster doses of vaccine: $\stackrel{\mathbb{Q}}{\Omega}$ between 3 and 5 years $(10,26)$.

Due to Service commitments in countries with a higher prevalence of hepatitis B infection than the UK, and to. conform with immunisation guidelines (27), it is $\vec{\omega}$ necessary to optimise the immunisation schedules in terms of producing long term protection and the cost of vaccine including booster doses. Therefore, it is essential to identify both non-responders and poor responders to vaccine among all Services health care personnel as $\rightarrow$ failure to do so may increase the occupational risk of infection with hepatitis $B$ virus.

\section{Acknowledgements}

The authors express their gratitude to the Direct oifs General Medical Services Army and RAF, and all Servige medical staff involved with the immunisation procedura, data collection and to laboratory staff at RAM College and RAF Halton.

The work reported in this paper was supported by Army Medical Services Research Executive under proje grant number 366.

\section{REFERENCES}

1. Dienstag JL, Ryan DM. Occupational exposure to윽 hepatitis B virus in hospital personnel: infection or immunisation? Am J Epidemiol 1982; 115:26-39.

2. DeINHARDT F, ZuCKERMAN AJ. Immunization against Hepatitis B: Report on a WHO meeting on Viral Hepatitis in Europe. J Med Virol 1985;17:209-217.

3. GUST I, CROWE S. The global importance of viral hepatitis. In: Clinics in Tropical Medicine ande Communicable Diseases 1986;1(2):281.

4. Al-Faleh FZ, Ayoola EA, Arif M, et al.홍 Seroepidemiology of Hepatitis B virus infection in Saudi Arabian children: a baseline survey for mass윽 vaccination against Hepatitis B. J Infect $1992 ;$ 24:197-206.

5. FaGAN EA, Tolley P, SMITH HM, et al. Hepatitis B vaccine: Immunogenicity and follow-up including two year booster doses in high-risk health care o personnel in a London Teaching Hospital. $J \operatorname{Med}_{N}$ Virol 1987; 21:49-56.

6. WALdRON HA. Antibody response to hepatitis vaccination. $B r$ J Ind Med 1990; 47:354-355. 
7. Westmoreland D, Player V, Heap D C, Hammond A. Immunization against hepatitis $B$ - what can we expect. Epidemiol Infect 1990; 104:499-509.

8. ROGAN PD, DUGUID JKM. Immunisation of staff of a regional Blood Transfusion Centre with a recombinant hepatitis B vaccine. $J$ Infect 1991; 22:5.

9. Hepatitis B vaccination. EMR Policy Letter $18 / 87$ (JS) 1987.

10. UK Health Departments. Immunisation against Infectious Disease. London HMSO, 1992.

11. International Advisory Group. Immunisation against Hepatitis B. Lancet 1988; i:875-876.

12. GLIM 3.77 (Generalised Linear Interactive Modelling). Numerical Algorithms Group Limited, Royal Statistical Society 1986.

13. HeAly MJR. GLIM: An Introduction. Oxford University Press 1988:80-99.

14. ZUCKERMAN AJ. Who should be immunised against Hepatitis B? Br Med J 1984; 289:1243-1244.

15. Hu DJ, Kane MA, Heymann DL. HIV, Hepatitis B virus and other blood borne pathoens in health care setting, a review of risk factors and guidelines for prevention. Bull WHO 1991;69:623-630.

16. LaUkamm-Josten U, von Laer G, Feldmeier $\mathrm{H}$, e $t$ al. Active immunisation against hepatitis $B$ : Immunogenicity of a recombinant DNA vaccine in females, heterosexual and homosexual males. Postgrad Med J 1987; 63 (suppl 2): 143-146.

17. Alper CA, Kruskall MS, Marcus-Bagley D, et al. Genetic prediction of non-response to hepatitis B vaccine. $N$ Engl J Med 1989; 321:708-712.

18. Horowitz MM, Ershler WB, MCKinney WP, BatTIOLA RJ. Duration of Immunity after Hepatitis B vaccination; Efficacy of low-dose booster vaccine. Ann Intern Med 1988; 108:185-189.

19. Weber DJ, Rutula WA, Samsa GP, Santimaw JE, LEMOM S M. Obesity as a predictor of poor antibody response to hepatitis B plasma vaccine. JAMA 1985; 254:3187-9.

20. Corrao G, Celleri M, Zotti M, et al. Immune response to anti-HBV vaccination: study of conditioning factors. Eur J Epidemiol 1988; 4:492496.

21. Nowicki MJ, Tony MJ, BoHman RE. Alterations in the immume response of nonresponders to the Hepatitis B vaccine. J Infect Dis 1985; 152(6):12451248.

22. Berridge DC, Galea MH, Evans DF, Pugh S, HoPKINSON BR, MAKIN GS. Hepatitis B immunization in vascular surgeons. Br J Surg 1990; 77:585-586.

23. Williams JR, Flowerdew ADS. Uptake of immunisation against hepatitis $B$ among surgeons in Wessex Regional Health Authority. Br Med J 1990; 301:154.
24. KinNersLey P. Attitudes of general practitioners towards their vaccination against hepatitis B. $\mathrm{Br} \mathrm{Med}$ $J$ 1990; 300: 238.

25. Porteous MJ LeF. Operating practices of and precautions taken by orthopaedic surgeons to avoid infection with HIV and Hepatitis B virus during surgery. Br Med J 1990; 301: 167-9.

26. Joint Working Party of the Hospital Infection Society and the Surgical Infection Study Group. Risks to surgeons and patients from HIV and hepatitis: guidelines on precautions and management of exposure to blood or body fluids. Br Med J 1992; 305: $1337-42$.

27. NHS Management Executive. Protecting Health Care Workers and Patients from Hepatitis B. HSG(93)40: August 1993.

28. Heptonstall J. Outbreaks of Hepatitis B virus infection associated with infected surgical staff. Communicable Disease Report 1991; 1:R81-R85.

29. Delamothe T. Hepatitis B and exposure prone procedures. BR Med J 1994; 309:73.

30. Choudhary RP, Cleator SJ. An examination of needlestick injury rates, hepatitis $B$ vaccination uptake and instruction on 'sharps' technique among medical students. J Hosp Infect 1992; 22:143-148.

31. AstBURY C, BAXTER PJ. Infection risks in hospita官 $\vec{c}$ staff from blood: Hazardous injury rates and acceptance of hepatitis B immunisation. $J$ Soc Occup Med 1990; 40:92-93.

32. Polakoff S. Acute viral hepatitis B reported to the Public Health Laboratory Service. J Infect 1990 20:163-168.

33. Werner BG, Grady GF. Accidental hepatitis B? surface antigen positive inoculations. Use of e antigen to estimate infectivity. Ann Intern Med 1982; 97:367369.

34. EDMONDSON-JONES JP. An Investigation to determine which members of the Defence Medical Services require vaccination to prevent infection by Hepatitis B virus. MSc Thesis 1986.

35. Maynard JE. Hepatitis B: Global importance and need for control. Vaccine 1990; 8:Suppl S18-S20.

36. Harries AP, Clark M, Beeching NJ, Lavelle J, MutTon KJ. Early anti-HBs antibody response to accelerated and to conventional hepatitis $B$ vaccination regimens in healthy persons. J Infect 1991; 23:251-254.

37. Morris DJ, O'Neil EM, McCloy EC, Hui E, GATLEY MS. Hepatitis B surface antibody responses following accelerated vaccination. $J$ Hosp Infect 1993; 23:317-319.

38. JiLG W, SChmidt M, Dienhardt F. Vaccination against hepatitis $\mathrm{B}$ : comparison of three different vaccination schedules. J Infect Dis 1989; 160:766769. 